\title{
Synthetic biology and the ethics of knowledge
}

\author{
Thomas Douglas and Julian Savulescu \\ Oxford Uehiro Centre for Practical Ethics, Faculty of Philosophy, University of Oxford, Oxford, UK
}

\begin{abstract}
Synthetic biologists aim to generate biological organisms according to rational design principles. Their work may have many beneficial applications, but it also raises potentially serious ethical concerns. In this article, we consider what attention the discipline demands from bioethicists. We argue that the most important issue for ethicists to examine is the risk that knowledge from synthetic biology will be misused, for example, in biological terrorism or warfare. To adequately address this concern, bioethics will need to broaden its scope, contemplating not just the means by which scientific knowledge is produced, but also what kinds of knowledge should be sought and disseminated.
\end{abstract}

It's 2020. Designer viruses are now used to treat some cancers and infectious diseases. But they're expensive and difficult to manufacture. An old college friend of yours, an eminent synthetic biologist, calls you for advice. She's discovered a new, cheap way to produce synthetic viruses using out-of-date bench top DNA synthesisers that are now ubiquitous, even in developing countries. She's excited about the discovery and is hoping to publish it in Nature. She thinks it could bring a wide range of medical treatments, not to mention research tools, within the grasp of the developing world. There's just one catch. Every major military and terrorist group in the world has access to these obsolete synthesisers. It would take only one malevolent agent and one such machine to produce enough vaccine-resistant smallpox virions to devastate humanity.

Synthetic biology is a new discipline that aims to apply engineering principles to the creation of biological systems. Significant milestones achieved to date have included the development of a registry of standardised biological parts and the creation of a replicating bacterium with a chemically synthesised genome. ${ }^{12}$ The discipline has captured the interest of policymakers, science funders and the media, and is beginning to attract interest from bioethicists. ${ }^{3}{ }^{5}$ However, it remains unclear what bioethical analysis, if any, this new discipline requires.

In this article, we argue that the most important issue for bioethicists to address is the concern that knowledge from synthetic biology will be deliberately misused. Most bioethicists would be unprepared to respond in a well thought out way to the hypothetical situation with which we began this article. Questions about when to create or disseminate dangerous scientific knowledge have not made it on to the agenda of mainstream bioethics. In our view, the advent of synthetic biology creates strong reasons to remedy this situation by developing an 'ethics of knowledge'. But before arguing for that view, we will define

Correspondence to Dr Thomas Douglas, Oxford Uehiro Centre for Practical Ethics, Faculty of Philosophy, University of Oxford, Suite 8, Littlegate House, 16/17 St Ebbe's Street, Oxford OX1 1PT, UK; thomas.douglas@philosophy.ox.ac.uk.

Competing interests None.

Provenance and peer review Not commissioned; not externally peer reviewed. 
synthetic biology, sketch what the discipline has achieved and outline the promises it holds for the future.

\section{SYNTHETIC BIOLOGY}

There is, as yet, no widespread agreement on a definition for synthetic biology. On a broad definition, it may be understood as encompassing all attempts to create biological systems, organisms or their components (including genomes) de novo or using rational design principles. However, we wish to capture what is new and controversial about synthetic biology, so we will opt for the following narrower definition that focuses on the creation of novel entities:

Synthetic biology is that branch of research and development that applies rational design principles to produce novel biological systems, organisms, or components de novo, or that contributes in a direct and significant way to their production through the novel development of materials, technologies or processes.

One prominent strand of work in synthetic biology aims to create a range of standardised biological parts or modules that can be tacked on to bacterial chassis to produce customised biological systems. MIT has built a registry of over 3000 such modules, known as BioBricks, which are available as an open source resource. ${ }^{1}$ Meanwhile, advances in genome synthesis and transplantation may ultimately enable the creation of novel bacterial chassis. The first full gene was synthesised four decades ago. ${ }^{6}$ However, this took years. Today's synthetic biologists aim to rapidly synthesise full genomes by stitching together shorter sequences. In 2002, Eckard Wimmer and collaborators reported the synthesis of the $7.5 \mathrm{~kb}$ poliovirus genome in around a year. ${ }^{7}$ The following year, Craig Venter's group reported that it had synthesised the (slightly smaller) $\varphi$ X174 bacteriophage virus in a matter of weeks. ${ }^{8}$ As well as increasing the speed of synthesis, researchers have also been able to produce larger genomes. In early 2008, Venter's group succeeded in synthesising a full bacterial genome ${ }^{9}$ and in May 2010 it announced the creation of the first living and replicating bacterium with a synthetic genome. ${ }^{2}$ Though this bacterium differs only slightly from wild-type Mycoplasma mycoides, it arguably constitutes 'proof of principle' for the synthesis of a new bacterial chassis or other radically new bacteria-bacteria which have not and could not have naturally existed.

Other synthetic biologists are seeking even more fundamental re-design of life. Floyd Romesberg and colleagues have successfully developed two new bases which can be incorporated into DNA alongside the existing four bases, and can be replicated by naturally occurring enzymes. ${ }^{10}$ Though potential applications of the new bases remain unclear, the development suggests the possibility that we may be able to create DNA with highly unusual characteristics. Meanwhile, members of the PACE (Programmable Artificial Cell Evolution) consortium have taken the first steps towards developing life-like 'protocells' that use peptide nucleic acid rather than DNA as the information-storing molecule. ${ }^{11}$

Though synthetic biologists face significant challenges, ${ }^{12}$ it is hoped that progress will lead to the development of new drugs, vaccines and diagnostic technologies. One possibility is that synthetic agents will be used as targeted cancer treatments. It has been shown that certain wild-type bacteria colonise tumours and exert an anti-cancer effect. ${ }^{13}$ Synthetic techniques may allow the creation of agents that localise to and attack cancer cells more selectively. ${ }^{14}$

In addition, synthetic microbes could be used to manufacture drugs or other chemicals (table 1). DuPont is already using semi-synthetic bacteria to convert corn sugar into a chemical it 
uses to make fabrics. Meanwhile, several companies are researching the possibility of using synthetic agents to generate biofuels. ${ }^{15}$

Other environmental applications may also be possible. Scientists have produced semisynthetic microbes capable of detecting light, explosives, metabolites and the differences between espresso, coffee and decaf. ${ }^{16}{ }^{18}$ These developments raise the possibility that synthetic microbes could also be used to detect environmental toxins. A further environmental application may be the deactivation of environmental toxins or pollutants, including mopping up oil spills. Researchers at Berkeley have engineered a semi-synthetic bacterium which can degrade the insecticide paraoxin. ${ }^{19}$

Further into the future, even more radical applications may be possible. Some hope that synthetic biology will enable the development of biological cameras, computers, or robots, and a transatlantic project is currently pursuing the development of synthetic art. ${ }^{24}$

\section{ETHICAL CONCERNS}

Synthetic biology holds out the prospect of significant benefits to humanity. However, it also raises some important concerns. These include, for example, concerns about laboratory biosafety, the aggravation of injustices and challenges that the discipline may pose to existing systems of intellectual property rights. However, in our view, there are three concerns that are likely to garner most attention from bioethicists: (1) concerns about 'playing God', which have been prominent in closely related areas of science; (2) concerns about undermining the distinction between living things and machines, which attracted early attention from ethicists ${ }^{25}$; and (3) concerns about the deliberate misuse of knowledge from synthetic biology, which have been among the most prominent concerns raised by nonethicists. We will argue that, whereas the first two concerns have only weak claims to attention, the third demands significant ethical analysis.

\section{Playing God}

Concerns about humans playing God can be understood in at least two different ways. On a religious interpretation, the concern is that humans are literally usurping the role of some higher being or god. This worry is often raised about attempts to alter natural genomes, so it would be surprising if it were not raised about attempts to design entirely new genomes. On secular interpretations, the concern is typically with humans failing to recognise their own limitations, for example, by overestimating their ability to control complex ecosystems. ${ }^{26}$ Again, we can imagine the same charge being made against synthetic biologists.

Though concerns about playing God are not new with synthetic biology, the discipline may allow us to play God in qualitatively different ways. Humans have long been able to exert some influence on the genetic make-up of future beings through selective breeding; however we were constrained to working within the timescales and genetic possibilities dictated by evolution. Genetic engineering partially freed us from this constraint. Synthetic biology promises to free us from a further constraint: the need for a natural template on which future organisms must be based. It will allow us to design and create life, not merely to tinker with or modify it.

There is another important respect in which synthetic biology differs from earlier enterprises deemed to involve playing God: it will enable us to create life from non-living, inorganic matter. Indeed, this is arguably the most distinctive role of synthetic biology, and it is a role that might well be assigned to God (or thought to require particular sensitivity to human limitations). 
The advent of synthetic biology could thus be viewed as a significant leap towards usurping the functions of God (or overstepping human limitations). It might therefore be argued that there is a need for specific ethical analyses of playing God concerns as applied to synthetic biology. However, we find it difficult to see what these analyses would add. After all, the basis of the concern about playing God remains the same in synthetic biology as it is elsewhere. The concern about modification was that it might involve usurping the role of a higher being or failing to recognise human limitations; the concerns about design and the de novo creation of life are precisely the same. Moreover, it is plausible that the modification, design and creation of life either all involve some problematic form of playing God, or they all do not: they all involve taking on functions that are often attributed to gods and that require sensitivity to human limitations, but they might also all be defended on the grounds that they will promote wellbeing if proper caution is taken, are consistent with natural or god-given desires for improvement of the human condition and involve working with materials and intellectual resources that God supposedly gave us. It is not as though synthetic biologists could literally create something from nothing. ${ }^{i}$ It is therefore unclear what discussions of 'playing God' in relation to synthetic biology would add to earlier discussions of the concern in relation to other practices.

\section{Organisms or machines?}

A unique ethical concern about synthetic biology is that it may result in the creation of entities which fall somewhere between living things and machines.

It is not difficult to see why some products of synthetic biology might fail to fit comfortably into our intuitive dichotomy between the living and the non-living. Consider, for example, the bacterial bio-factories that synthetic biologists hope to construct by adding suitable modules to a minimal bacterial chassis. These bio-factories might possess many of the characteristics that we ordinarily take to be definitive of life: for example, homeostatic physiological mechanisms, a nucleic acid genome and protein-based structure, and the ability to reproduce. But they would also possess many of the features characteristic of machines: for example, modular construction, based on rational design principles, and with specific applications in mind. Alternatively, consider the more remote but not entirely fantastic possibility of a synthetic bio-computer which performs many of the tasks currently performed by PCs, but which is based not on the silicone chip, but on neural networks composed of synthetic human nerve cells.

Entities such as these certainly test our intuitive dichotomy between the living and the nonliving in ways that it has hitherto not been challenged. What is less clear, however, is that difficulties about how to classify synthetic entities present any ethical objection to producing them.

One concern could be that creating organisms with the features of both organisms and machines will change how we view existing kinds of life. Mildred Cho and collaborators worry that it will lead us to adopt a wrongheaded reductionist account of life, according to which life is nothing more than a set of biochemical components, or, more restrictively, a set of genes. This, in turn, will undermine 'the special status of living things and the value that we ascribe to life' ${ }^{25}$ The concern here appears to be that we will cease to regard the distinction between living things and machines as important. But— the argument would go - this distinction is important, for machines and living things differ significantly in their moral status. Machines, such as computers, have no intrinsic value (they are valuable only insofar they can be used to bring about valuable ends), no interests and no rights.

\footnotetext{
i Thanks to Abraham Steinberg for this point.
} 
Organisms, on the other hand, may possess all of these things. Thus, if the significance attached to the distinction between living things and machines were eroded, we might wrongly come to see living things as possessing less moral status than they actually have.

This argument seems to overblow the significance of life, however. There are many living things (bacteria, for example) to which we already ascribe no moral status. We feel quite justified in killing or exploiting bacteria whenever it suits us. We certainly do not think that in doing so we a breaching their rights, obstructing their interests, or denying their intrinsic value: bacteria possess none of these things. This is because moral status is conferred not by life, but by characteristics that some living things possess (sentience, consciousness, selfconsciousness and rationality are among the most obvious candidates).

Perhaps the concern can be re-stated in a more plausible form. It could be argued that accepting reductionist accounts of life would lead us to underestimate the moral status of those living things that do possess moral status. However, it is unclear why this should necessarily be. Many people already accept reductionist accounts of life while still regarding at least some conscious beings as having special moral status. ${ }^{27}$

The real concern in this area is not that we will come to underestimate the moral status of existing living things, but that we will misjudge the moral status of some of the new entities that synthetic biologists may produce. We are, after all, often uncertain or mistaken in our assignments of moral status. While we can be confident that persons have significant moral status, and machines do not, there is plenty of grey area in between where we are less certain. To see this, we need only to survey the literature on the moral status of non-human animals and human embryos. Moreover, it seems plausible that many synthetic entities would fall within this grey area. Perhaps we could be confident that a minimal bacterial chassis would possess no significant moral status. But we might be less confident about a bio-computer constructed from synthetic human-like nerve cells. Arguably, we should not create such a being until we have ascertained what moral status it would have, and thus, how we should treat it.

Synthetic biology may, then, highlight the need for more secure accounts of what determines moral status than we currently have. However, the ethical work necessary to develop such accounts is already underway. Ethical controversies about abortion, stem cell research, human-nonhuman chimeras, artificial intelligence and the treatment of animals have ensured that questions about moral status enjoy a high priority on the bioethics agenda. Discussion of the determinants of moral status has even made its way into recent debate on the ethics of cognitive enhancement. ${ }^{28} 29$ Those reflecting about the direction of synthetic biology will be able to piggyback off a rich and thriving literature on moral status. The need for specific attention to the moral status issues raised by synthetic biology is limited.

\section{The misuse of knowledge}

A third concern about synthetic biology has been that the knowledge it produces might be intentionally misused. Two ground breaking studies last decade reported the de novo synthesis of human pathogens- the poliovirus, ${ }^{7}$ and the 1918 Spanish influenza virus. ${ }^{30}$ These studies raise the prospect that states or terrorist cells without access to wild-type viruses might acquire the ability to create human pathogens for use in biological weapons. Further into the future, synthetic biology may enable the creation of novel pathogens more deadly than any known before. Scientists have already accidentally created a vaccine resistant strain of the mousepox virus through more traditional genetic engineering techniques. ${ }^{31}$ This killed $100 \%$ of mice infected. The mousepox virus is not a human pathogen, but the same technique might also render viruses that do affect humans, such as smallpox, vaccine resistant. Prior to eradication by vaccination, smallpox was the scourge of 
humanity killing about a third of all affected people in a horrible manner. If the results of the mousepox experiment applied to smallpox, it would be possible to significantly increase its lethality and render it vaccine resistant. If the incubation period, almost ideal already for terminal pandemic, could be further increased, it may become possible to produce a bioweapon capable of devastating humanity. The virus could be released at airport terminals, stadiums, train stations and public events. Thousands could potentially be infected at such loci and the virus might be spread during the incubation period all around the world, before any pandemic could be detected.

Synthetic biology may ultimately pose what has become known as the dual-use dilemma. ${ }^{3} 32$ This can be understood as the dilemma arising when scientific knowledge could be used in both good and harmful ways and the risk of harmful use is sufficiently high that it is no longer clear whether that knowledge should be pursued or disseminated. Some nuclear physicists working in the first half of last century explicitly took themselves to be grappling with this dilemma in deciding whether to assist in the development of nuclear fission technology. Various well-established areas of biomedical research might also be thought to raise dual-use dilemmas: for example, work on behavioural genetics and racial differences in intelligence and character; research into lie-detection, DNA fingerprinting and biometrics; and traditional forms of genetic engineering (which, like synthetic biology, raise concerns about bioweapon production). However, for whatever reason, the dual-use dilemma has failed to capture the interest of many bioethicists. Research ethics, the branch of mainstream bioethics under whose jurisdiction the dual-use dilemma falls, has been concerned primarily with the ethics of how scientific research will be conducted and to a lesser degree with whether the research is likely to produce any new knowledge (ie, with whether it has any scientific merit). With a few recent exceptions, ${ }^{34} 3334$ questions about whether it is ethical to produce and/or disseminate that knowledge are generally neglected altogether.

Perhaps, in established areas of science, it can be held that there is no significant chance that the risk of misuse outweighs the beneficial uses of the research. There is thus no serious possibility of a genuine dual-use dilemma arising. However, in synthetic biology it is less clear that this is so. It is of course important not to overstate the risks. Synthesising dangerous pathogens is one thing, weaponising them is another. ${ }^{35}$ Moreover, any attempt to synthesise designer pathogens would be constrained by our limited understanding of how various factors combine to make a pathogen dangerous. Finally, there is the question of whether engaging in high-tech synthetic techniques would be a cost-effective option for potential bioweapon proliferators, particularly terrorist cells with limited resources. However, it seems possible that in the future, technological advances and cost reductions will bring bioweapon development using synthetic techniques within the abilities of smaller and smaller groups, perhaps even lone 'bio-hackers'. Indeed, as Michael Selgelid has noted, there are some reasons to think that the threat posed by the misuse of knowledge from synthetic biology will ultimately be greater than that posed by nuclear technology. ${ }^{4}$ First, though nuclear technology is likely to remain bulky and expensive, the technologies required to produce bioweapons may become quite portable and cheap. Second, in contrast to advances in nuclear technology, which were often classified and confidential from the outset, there has been a strong tradition of openness in the life sciences, meaning that much of the background knowledge relevant to synthetic biology is already in the public domain. Given this, it would be a bold move indeed to disregard the possibility of dual-use dilemmas arising in synthetic biology.

The dearth of existing bioethical work on the dual-use dilemma combined with the prospect that synthetic biology will pose such dilemmas creates a strong prima facie case for bioethical attention. What seems called for is an attempt to confront questions about the ethics of producing and disseminating certain types of scientific knowledge, not merely the 
ethics of how scientific knowledge is produced. Ethicists could, for example, seek to develop principles for determining when producing or disseminating dangerous knowledge is impermissible. In recent years, a few preliminary forays have been made in this direction. ${ }^{3}$ 43334 We believe that such efforts should be continued and strengthened.

In what follows, we will attempt to buttress the case for an 'ethics of knowledge' by first drawing out its practical importance and second defending it against objections.

\section{THE PRACTICAL IMPORTANCE OF AN ETHICS OF KNOWLEDGE}

There are two considerations that, in our view, make the ethics of knowledge a matter of practical importance. First, concerns about misuse of knowledge from synthetic biology are already driving, and will continue to motivate, new risk reduction strategies that could have substantial effects on scientific progress. Second, ethicists are well placed to contribute positively to the selection of appropriate strategies.

In the wake of the mousepox and poliovirus studies mentioned earlier, a number of strategies for reducing the risk posed by synthetic biology have been suggested and implemented. Many of these are 'downstream' measures that seek to leave the creation and propagation of scientific knowledge untouched. However, others are not. For example, some scientific journals have implemented internal screening procedures to ensure they do not publish material presenting an unacceptable risk of misuse, ${ }^{36}$ and some funding bodies have begun asking applicants to declare risks that their work will be misused. ${ }^{37}$ Governments have even got directly involved in influencing knowledge creation and dissemination. For example, a range of personnel vetting procedures for students and researchers have been implemented to prevent dangerous knowledge from falling into the wrong hands.

Risk reduction strategies will no doubt continue to include attempts to influence knowledge creation and dissemination. This suggests an important role for an ethics of knowledge: it could help to inform decisions between alternative strategies. We can distinguish between three broad approaches:

1. A laissez faire approach—scientists and their institutions are left to deal with (or ignore) the concerns about misuse as they see fit.

2. A requirement for consideration—scientists and/or their institutions are required to assess the risk of misuse posed by their work, but are left free to respond as they see fit.

3. A requirement for independent consideration—certain projects/findings must be considered by an independent body before being funded, undertaken, or published.

If either the second or third approach is adopted, a further choice will arise regarding what test, if any, should be applied in considering the risk of misuse. For example, should it be required that there be no serious risk of harm (a precautionary test), that the expected benefits of the research outweigh the expected harms (a harm-benefit test), or merely that there be no clear and immediate risk of misuse (a proactionary test)?

Decisions between these approaches and tests should depend in part on empirical facts. For example, if humans are prone to overstate the risks or understate the benefits of knowledge, then a precautionary or even a harm-benefit test might excessively stifle scientific progress. However, questions of value are also central. For example, in many cases, attempting to influence knowledge creation or dissemination in synthetic biology would promote one value-security - at the expense of others, such as economic growth, scientific freedom and the intrinsic value of knowledge. It is frankly implausible that scientific freedom or knowledge are absolute values or trump values. Some weighing must be done in relation to 
other values. The question is how. Ethicists are uniquely placed to settle such evaluative questions.

Of course, weighing values such as security and scientific freedom against one another is difficult. But that provides no reason to shy away from the challenge. In other areas, ranging from climate change policy, to international peace-keeping, to pandemic planning, the weighing of disparate values is required. Yet in those areas, there is generally taken to be an important role for ethicists in clarifying the values at stake, and offering arguments as to how they should be weighed. We claim that ethical analysis should play a similar role in relation to the values promoted and threatened by knowledge from synthetic biology.

\section{DEFENDING THE CASE FOR AN ETHICS OF KNOWLEDGE}

We have argued that, whereas other prominent concerns about synthetic biology have only limited claims to bioethical study, concerns about the misuse of knowledge warrant an indepth analysis. Indeed, they warrant a significant expansion of the scope of bioethics to incorporate an ethics of knowledge. Several objections could be advanced against this claim.

\section{'The focus should be on downstream solutions'}

In most cases where scientific knowledge can be misused there are strategies available for minimising the risk of misuse once the knowledge has been created and disseminated. The recent flurry of work on synthetic biology by policymakers, ${ }^{38} 41$ science funders ${ }^{42}$ and social scientists ${ }^{43}{ }^{45}$ has focused largely on such strategies. In 2006, a Guardian journalist ordered a segment of the smallpox virus genome and succeeded in having it delivered to his home address ${ }^{46}$; perhaps better regulation of DNA sales or benchtop DNA synthesisers ${ }^{47} 49$ could prevent the distribution of such sequences. At a state level, strong enforcement of the biological and chemical weapons conventions could mitigate risks of misuse.

Arguably, were bioethicists to take seriously questions about whether and when scientific knowledge should be pursued and disseminated, this would distract attention from attempts to find 'downstream' strategies for preventing misuse. This would be a serious cost. The best way out of the dual-use dilemma is not to limit scientific work and publication, but to find some way of preventing information from being misused once it is widely known.

It should be recognised, however, that it may not always be possible to reduce the risk that some piece of knowledge will be misused to the point that the prospects of beneficial uses clearly outweigh the risk of misuse. One of the reasons why early nuclear physics posed a dual-use dilemma was that it was not at all clear how the misuse of nuclear technology could, given the geo-political considerations in play, be prevented. Similarly, there are concerns about the extent to which it will be possible to prevent the misuse of knowledge from synthetic biology. Given these difficulties, we should at least remain open to the possibility that, for some types of work in synthetic biology, the risks of misuse may be so high as to make pursuing that work, or disseminating its results, ethically problematic.

There is, moreover, little risk that discussing this possibility will significantly deflect attention from the task of finding novel downstream regulatory and technological solutions. The debate on synthetic biology to date is remarkable for the extent to which it has been dominated not by ethicists, but by scientists, social scientists and policymakers-those in the best position and with the strongest incentive to develop such solutions.

\section{'Scientists are not morally responsible for how their work is used'}

A second objection to our claim appeals to the view that scientists are not typically morally responsible for how the knowledge they produce gets used. Rather, the responsible parties 
are those who use, or regulate the use of, that knowledge. It could be argued that bioethicists, and others who ethically appraise scientists' work, should therefore leave questions about the misuse of knowledge to political theorists and philosophers of technology.

This objection fails for three reasons. First, it is not clear that scientists are always entirely free from moral responsibility for how the knowledge they produce gets used. Defenders of the arms industry sometimes claim that arms manufacturers and dealers are not morally responsible for the misuse of the weapons they make and trade since they do not themselves misuse the weapons. But this claim is frequently regarded as implausible. In many cases the risk of misuse is sufficiently evident and avoidable that arms manufacturers and dealers bear some responsibility for it. Similar thoughts could in principle apply to some future programmes in synthetic biology.

Second, even if scientists are not responsible for uses of the knowledge they produce, those uses might still be relevant to ethical appraisals of their work. It is important to distinguish between two different types of ethical appraisal: assessments of praiseworthiness and blameworthiness, and assessments of rightness and wrongness. Suppose you perform some act with the effect that, some way down the causal line, event $E$ occurs. If you are not responsible for $E$, it may follow that you should not be praised or blamed for its occurrence. But it does not follow that the occurrence of $E$ is irrelevant to the rightness or wrongness of your action. Enabling some good outcome may be the right thing to do even if not praiseworthy, and enabling a bad outcome may be wrong even if not blameworthy. Thus, showing that scientists would not be responsible for misuse of their work does not settle the question whether it would be right or wrong for them to proceed with it.

Third, ethically appraising the work of scientists is not the only task for bioethics. Bioethics is also concerned, for example, with the assessment of biomedical science policy and regulations. Even if the misuse of scientific knowledge is irrelevant to the ethical assessment of actions of individual scientists, it might still be relevant to the assessment of policies that promote, impede and regulate the production of that knowledge.

\section{'Knowledge is intrinsically valuable'}

In response to concerns about the misuse of science, it is sometimes claimed that the aim of science is merely to produce knowledge, not to benefit humanity. Sometimes this response is only hinted at, for example, by attempting to draw a sharp line between science (which aims at knowledge production) and technology (which attempts to harness that knowledge for the benefit of humanity). Other times, it is stated more baldly. Robert Oppenheimer, the head of the Manhattan project, put it like this: 'When you see something that is technically sweet, you go ahead and do it and you argue about what to do about it only after you have had your technical success'. 50

Of course, claims about what scientists aim to do are descriptive, not normative. However when they are invoked to diffuse ethical criticism, it seems reasonable to regard them as normative claims in disguise. Perhaps the thought is really that science is justified merely in virtue of its ability to produce knowledge, not in virtue of how that knowledge will or may be used. This normative claim could be buttressed by appealing to the widely held though philosophically controversial view that knowledge has intrinsic value: it has value that is independent of its valuable uses.

Note, however, that even if knowledge is intrinsically valuable, it will not follow that valuable and dis-valuable applications of that knowledge can simply be ignored. A more natural conclusion would be that the intrinsic value of knowledge should be considered 
alongside its instrumental (dis)value. To obtain the result that the uses of knowledge can be ignored, it would have to be held that the intrinsic value of knowledge is a kind of trump value- a value that can be assumed at the outset to outweigh any conflicting disvalues. But, as we have already suggested, this is wildly implausible. Though we may never possess it, we can at least conceive of knowledge that would render the destruction of humanity both inexpensive and technically easy, and thus render the destruction of humanity extremely likely. Surely no amount of intrinsic knowledge-value could outweigh that risk.

\section{FINAL COMMENTS}

In 1979, The Progressive magazine published the rough mechanism of the hydrogen bomb, complete with technical diagrams. In doing so, it arguably exposed one of the best kept secrets in scientific history: at the time of publication, only four governments were thought to be in possession of it. The magazine argued that nuclear secrecy was fuelling the cold war by enabling nuclear policy to be determined by a security elite without proper public scrutiny. It was argued that the cost of publishing the mechanism-potentially aiding countries such as India, Pakistan and South Africa in acquiring H-bombs-was outweighed by the benefits of undermining that secrecy.

No similarly sensational revelations could be made about synthetic biology: there are no great secrets to reveal. And if synthetic biologists make discoveries with potentially devastating applications, these will most likely be released through a trickle of mainstream scientific publications, not through a single bold and conclusive act. But such knowledge may be a part of the blueprint for humanity's destruction, easily pieced together by fanatics, psychopaths or ideologues.

Bioethicists should begin to confront these issues now by considering not merely the ethics of how scientific knowledge is produced, but also ethical questions about whether to pursue and disseminate certain kinds of knowledge. This will help to inform the selection of risk reduction strategies that will inevitably be adopted in relation to synthetic biology, and perhaps ultimately other disciplines susceptible to misuse.

Though synthetic biology is not the first life science discipline to raise questions about the ethics of pursuing and dissemination knowledge, the fact is that these questions about pursuing and disseminating knowledge have not been addressed in depth by bioethicists. The advent of synthetic biology should be seen as both presenting an opportunity and escalating the need to address this neglect. A starting point could be to develop strategies for identifying and weighing the various values at stake in dual-use dilemmas.

\section{Acknowledgments}

We would like to thank Katrien Devolder for providing comments on a draft of this paper.

Funding The authors received funding from the University of Oxford, Christ Church, and the Wellcome Trust ('grant number WT086015).

\section{REFERENCES}

1. Massachusetts Institute of Technology. Registry of standard biological parts. http://partsregistry.org/ Main_Page (accessed 4 Jun 2010).

2. Gibson DG, Glass JI, Lartigue C, et al. Creation of a Bacterial cell controlled by a chemically synthesized genome. Science. 2010; 329:52-6. [PubMed: 20488990]

3. Miller, S.; Selgelid, MJ. Ethical and philosophical consideration of the dual-use dilemma in the biological sciences: report prepared by the Centre for Applied Philosophy and Public Ethics for the 
National Security Science and Technology Unit. Centre for Applied Philosophy and Public Ethics; Canberra: 2006.

4. Selgelid MJ. A tale of two studies: ethics, bioterrorism, and the censorship of science. Hastings Cent Rep. 2007; 37:35-43. [PubMed: 17649901]

5. The Hastings Center. Ethical issues in synthetic biology. http://www.thehastingscenter.org/ Research/Detail.aspx?id=1548 (accessed 4 Jun 2010).

6. Agarwal KL, Büchi H, Caruthers MH, et al. Total synthesis of the gene for an alanine transfer ribonucleic acid from yeast. Nature. 1970; 227:27-34. [PubMed: 5422620]

7. Cello J, Paul AV, Wimmer E. Chemical synthesis of poliovirus cDNA: generation of infectious virus in the absence of natural template. Science. 2002; 297:1016-18. [PubMed: 12114528]

8. Smith HO, Hutchison Iii CA, Pfannkoch C, et al. Generating a synthetic genome by whole genome assembly: X174 bacteriophage from synthetic oligonucleotides. Proc Natl Acad Sci. 2003; 100:15440-5. [PubMed: 14657399]

9. Gibson DG, Benders GA, Andrews-Pfannkoch C, et al. Complete chemical synthesis, assembly, and cloning of a Mycoplasma genitalium genome. Science. 2008; 319:1215-20. [PubMed: 18218864]

10. Leconte AM, Hwang GT, Matsuda S, et al. Discovery, characterization, and optimization of an unnatural base pair for expansion of the genetic alphabet. J Am Chem Soc. 2008; 130:2336-43. [PubMed: 18217762]

11. PACE Consortium. PACE Report. 2009 http://www.istpace.org//index.html (accessed 4 Jun 2010).

12. Kwok R. Five hard truths for synthetic biology. Nature. 463:288-90. [PubMed: 20090726]

13. Pawelek JM, Low KB, Bermudes D. Bacteria as tumour-targeting vectors. Lancet Oncol. 2003; 4:548-56. [PubMed: 12965276]

14. Anderson JC, Clarke EJ, Arkin AP, et al. Environmentally controlled invasion of cancer cells by engineered bacteria. J Mol Biol. 2006; 355:619-27. [PubMed: 16330045]

15. Weiss R. Synthetic DNA on the brink of yielding new life forms. Washington Post. 2007:A01.

16. Levskaya A, Chevalier AA, Tabor JJ, et al. Synthetic biology: engineering Escherichia coli to see light. Nature. 2005; 438:441-2. [PubMed: 16306980]

17. Looger LL, Dwyer MA, Smith JJ, et al. Computational design of receptor and sensor proteins with novel functions. Nature. 2003; 423:185-90. [PubMed: 12736688]

18. Voigt CA, Keasling JD. Programming cellular function. Nat Chem Biol. 2005; 1:304-7. [PubMed: 16408063]

19. de la Peña Mattozzi M, Tehara SK, Hong T, et al. Mineralization of paraoxon and its use as a sole $\mathrm{C}$ and $\mathrm{P}$ source by a rationally designed catabolic pathway in Pseudomonas putida. Appl Environ Microbiol. 2006; 72:6699-706. [PubMed: 17021221]

20. Martin VJJ, Pitera DJ, Withers ST, et al. Engineering a mevalonate pathway in Escherichia coli for production of terpenoids. Nat Biotechnol. 2003; 21:796-802. [PubMed: 12778056]

21. Pfeifer BA, Admiraal SJ, Gramajo H, et al. Biosynthesis of complex polyketides in a metabolically engineered strain of E coli. Science. 2001; 291:1790-2. [PubMed: 11230695]

22. Energy Biosciences Institute. Engineering a yeast strain that efficiently utilizes C5/C6 sugars. http://www.energybiosciencesinstitute.org/index.php? option=com_content\&task=view\&id=164\&Itemid=20 (accessed 4 Jun 2010).

23. Aleksic J, Bizzari F, Cai Y, et al. Development of a novel biosensor for the detection of arsenic in drinking water. Synthetic Biology, IET. 2007; 1:87-90.

24. EPSRC. Sandpit: synthetic aesthetics: connecting synthetic biology and creative design. http:// gow.epsrc.ac.uk/ViewGrant.aspx?GrantRef=EP/H01912X/1 (accessed 4 Jun 2010).

25. Cho MK, Magnus D, Caplan AL, et al. Ethical considerations in synthesizing a minimal genome. Science. 1999; 286:2087-9. [PubMed: 10617419]

26. Coady, CAJ. Playing God. In: Savulescu, J.; Bostrom, N., editors. Human enhancement. Oxford University Press; Oxford: 2009. p. 155-80.

27. Weinberg, S. Facing up: science and its cultural adversaries. Harvard University Press; Cambridge, MA: 2001.

28. Buchanan A. Moral status and human enhancement. Philos Public Aff. 2009; 37:346-81.

29. McMahan J. Cognitive disability and cognitive enhancement. Metaphilosophy. 2009; 40:582-605. 
30. Tumpey TM, Basler CF, Aguilar PV, et al. Characterization of the reconstructed 1918 Spanish Influenza pandemic virus. Science. 2005; 310:77-80. [PubMed: 16210530]

31. Jackson RJ, Ramsay AJ, Christensen CD, et al. Expression of mouse Interleukin-4 by a recombinant ectromelia virus suppresses cytolytic lymphocyte responses and overcomes genetic resistance to mousepox. J Virol. 2001; 75:1205-10. [PubMed: 11152493]

32. Parliamentary Office of Science and Technology. The dual-use dilemma. Parliamentary Office of Science and Technology; London: 2009.

33. Samuel GN, Selgelid MJ, Kerridge I. Managing the unimaginable: regulatory responses to the challenges posed by synthetic biology and synthetic genomics. EMBO Rep. 2009; 10:7-11. [PubMed: 19079130]

34. Kuhlau F, Eriksson S, Evers K, et al. Taking due care: moral obligations in dual use research. Bioethics. 2008; 22:477-87. [PubMed: 18959730]

35. McLeish C, Nightingale P. Biosecurity, bioterrorism and the governance of science: the increasing convergence of science and security policy. Research Policy. 2007; 36:1635-54.

36. Journal Editors and Authors Group. Uncensored exchange of scientific results. Proceedings of the National Academy of Sciences. 2003; 100:1464.

37. BBSRC, MRC, Wellcome Trust. Managing risks of misuse associated with grant funding activities: a joint BBSRC, MRC and Wellcome Trust policy statement. $2005 \mathrm{http}: / /$ www.bbsrc.ac.uk/web/FILES/Policies/misuse_of_research_joint.pdf (accessed 4 Jun 2010).

38. National Research Council. Biotechnology research in an age of terrorism. National Research Council of the National Academies, The National Academies Press; Washington, DC: 2004.

39. National Research Council. Globalization, biosecurity, and the future of the life sciences. National Academies Press; Washington, DC: 2006.

40. National Science Advisory Board for Biosecurity. Addressing biosecurity concerns related to the synthesis of select agents. National Science Advisory Board for Biosecurity; Bethesda, MD: 2006.

41. National Science Advisory Board for Biosecurity. Proposed framework for the oversight of dual use life sciences research: strategies for minimizing the potential misuse of research information. National Science Advisory Board for Biosecurity; Bethesda, MD: 2007.

42. Royal Society, Wellcome Trust. Do no harm: reducing the potential for the misuse of life science research. Royal Society; London: 2004.

43. Atlas RM, Dando M. The dual-use dilemma for the life sciences: perspectives, conundrums, and global solutions. Biosecur Bioterror. 2006; 4:276-86. [PubMed: 16999588]

44. Corneliussen F. Adequate regulation, a stop-gap measure, or part of a package? Debates on codes of conduct for scientists could be diverting attention away from more serious questions. EMBO Rep. 2006; 7:S50-4. [PubMed: 16819451]

45. Tucker JB, Zilinskas RA. The promise and perils of synthetic biology. New Atlantis. 2006; 12:2545. [PubMed: 16832953]

46. Randerson J. Lax laws, virus DNA and potential for terror. The Guardian. 2006

47. International Association of Synthetic Biology. Code of conduct for best practice in gene synthesis. http://www.ia-sb.eu/tasks/sites/synthetic-biology/assets/File/pdf/iasb_code_of_conduct_final.pdf (accessed 4 Jun 2010).

48. Maurer SM. Synthetic biology marketplace: screening out terrorists. Bioethics Forum. 2009 http:// www.thehastingscenter.org/Bioethicsforum/Post.aspx?id=4158 (accessed 4 Jun 2010).

49. Garfinkel MS, Endy D, Epstein GE, et al. Synthetic genomics: options for governance-report of the project synthetic genomics: risks and benefits for science and society. J Craig Venter Institute, Centre for Strategic and International Studies, Massachusetts Institute of Technology. 2007

50. Polenberg, R., editor. In the matter of J. Robert Oppenheimer: the security clearance hearing. Cornell University Press; Ithaca, NY: 2002. p. 41 
Table 1

Some potential applications of synthetic biology

\begin{tabular}{ll}
\hline Sector & Examples \\
\hline Medical & Anti-cancer viruses 1314 HIV treatments 18 \\
Industrial & Manufacture of drugs $2021_{\text {Fabric industry }}^{15}$ Biofuel manufacture 1522 \\
Environmental & Biosensors 161723 Deactivation of toxins 19 \\
\hline
\end{tabular}

